\title{
Prognostic value of epidermal growth factor receptors in gastric cancer: a survival analysis by Weibull model incorporating long-term survivors
}

\author{
Alexandre Andrade Anjos Jácome • Durval R. Wohnrath • Cristovam Scapulatempo Neto • \\ Estela C. Carneseca $\cdot$ Sérgio V. Serrano $\cdot$ Luciano Souza Viana $\cdot$ \\ João S. Nunes $\cdot$ Edson Z. Martinez $\cdot$ José Sebastião Santos
}

Received: 7 November 2012/Accepted: 3 January 2013/Published online: 28 February 2013

(C) The Author(s) 2013. This article is published with open access at Springerlink.com

\begin{abstract}
Background There is no consensus about the prognostic role of HER2 expression and that of other members of the EGFR family in gastric cancer patients. The aim of this study was to evaluate the prognostic value of the EGFR family in gastric cancer.

Methods This retrospective study included 201 patients with gastric and esophagogastric junction adenocarcinoma stages 0-IV (AJCC 6th edition) who underwent primary tumor resection. Tissues from primary tumors were analyzed by tissue microarray technology and immunohistochemistry. Correlations between receptor expression and
\end{abstract}

A. A. A. Jácome $(\bowtie) \cdot$ S. V. Serrano $\cdot$ L. S. Viana $\cdot$ J. S. Nunes Department of Medical Oncology, Barretos Cancer Hospital, Str. Antenor Duarte Villela, 1331, Barretos, SP 14784-400, Brazil e-mail: jacome@usp.br

D. R. Wohnrath

Department of Gastrointestinal Surgical Oncology, Barretos Cancer Hospital, Str. Antenor Duarte Villela, 1331, Barretos, SP 14784-400, Brazil

C. Scapulatempo Neto

Department of Pathology, Barretos Cancer Hospital, Str. Antenor Duarte Villela, 1331, Barretos, SP 14784-400, Brazil

E. C. Carneseca

Center for Researcher Support, Barretos Cancer Hospital, Str. Antenor Duarte Villela, 1331, Barretos, SP 14784-400, Brazil

E. Z. Martinez

Department of Social Medicine, School of Medicine, University of São Paulo at Ribeirão Preto, Av. Bandeirantes, 3900, 2nd

Floor, Ribeirão Preto, SP 14049-900, Brazil

\section{J. S. Santos}

Department of Surgery and Anatomy, School of Medicine, University of São Paulo at Ribeirão Preto, Av. Bandeirantes, 3900, 9th Floor, Ribeirão Preto, SP 14049-900, Brazil clinicopathological characteristics were performed according to the chi-square test. Survival analysis was calculated according to the Weibull model with a mixture model incorporating long-term survivors. Multivariate analysis of prognostic factors was performed by a regression model incorporating long-term survivors with the Weibull distribution.

Results Membrane expression of HER1, HER2, and HER4 were 9,17 , and $15 \%$, respectively. No membrane expression of HER3 was observed. Cytoplasmic expression of HER1, HER3, and HER4 were 45, 62, and $24 \%$, respectively. HER2 and HER3 expression were correlated $(p<0.001)$ and associated with intestinal-type histology $(p=0.001$ and $p<0.001$, respectively) and advanced age $(p=0.011$ and $p=0.008$, respectively). According to a regression model adjusted for age, surgical radicality, surgical modality, Laurén histology, adjuvant therapy, TNM stage, and receptor expressions, only TNM stage showed prognostic influence.

Conclusions According to analysis by a parametric model, the EGFR family did not have prognostic influence in the gastric cancer population studied. The data presented showed a correlation between HER 2 and HER 3 expression, which might suggest a potential role for HER2-HER3 heterodimerization inhibitors.

Keywords Stomach neoplasms - Epidermal growth factor receptor - HER2 - Survival analysis .

Microarray analysis

\section{Introduction}

The epidermal growth factor receptors HER1 (also denoted EGFR), HER2, HER3, and HER4 are involved in the 
pathogenesis and progression of solid tumors such as cancer of the breast, lung, bladder, colon, ovary, and stomach [1-3]. All these receptors, except HER3, share the same molecular structure, with an extracellular domain that binds to the ligand, a transmembrane portion, and an intracellular domain with tyrosine kinase activity.

The binding of different ligands to extracellular domains triggers intracellular signaling reactions involved in cell differentiation, proliferation, and survival. The binding of the ligand to the extracellular domain induces HER1 homodimerization and heterodimerization of the remaining receptors, especially HER2 [4, 5].

HER2 overexpression or amplification has a wellestablished prognostic role in breast cancer and is a predictive factor of the response to drugs that act on the receptor, such as trastuzumab and lapatinib [6, 7]. In gastric cancer, phase II studies have demonstrated the benefits of the use of trastuzumab and lapatinib for locally advanced and metastatic disease with HER2 overexpression or amplification [8, 9]. A phase III study has recently demonstrated a gain in overall survival with the addition of trastuzumab to chemotherapeutic treatment in patients with HER2-positive advanced gastric cancer, supporting the role of this receptor as a predictive factor of the response to antiHER2 drugs, although its prognostic role is still uncertain [10-14].

In addition to HER2, HER1 and HER3 have also been pointed out as prognostic factors in gastric cancer, although with important caveats regarding the methodological resources for evaluation [10, 12, 15-18]. HER4 has been little studied so far in gastric cancer, but seems to have different effects on survival according to the tumor evaluated [19-21].

The objective of the present study was to contribute to the investigation of the prognostic role of different receptors belonging to the EGFR family in patients with gastric cancer.

\section{Patients and methods}

This was a retrospective study involving 201 patients with stage 0-IV gastric and esophagogastric junction (EGJ) carcinomas with distant metastases (AJCC, 6th edition), who underwent gastrectomy or esophagogastrectomy during the period from 1 January 2006 to 21 December 2008 at the Barretos Cancer Hospital, Barretos, São Paulo, Brazil (Table 1) and for whom surgical specimens were available for protein determination.

After surgical treatment or adjuvant chemoradiotherapy, the patients were followed up with medical visits, physical examination, laboratory tests, and a chest X-ray at 3-month intervals during the first 2 years, at 4-month intervals during
Table 1 Characteristics of the patients

\begin{tabular}{|c|c|}
\hline Characteristics & Number $(\%)$ \\
\hline Total & $201(100)$ \\
\hline \multicolumn{2}{|l|}{ Gender } \\
\hline Male & $124(62)$ \\
\hline Female & $77(38)$ \\
\hline \multicolumn{2}{|l|}{ Age } \\
\hline Median & 62 \\
\hline Range & $27-88$ \\
\hline \multicolumn{2}{|l|}{ Tumor location } \\
\hline Stomach & $160(81)$ \\
\hline EGJ & $38(19)$ \\
\hline \multicolumn{2}{|l|}{ Laurén's histology } \\
\hline Intestinal type & $124(63)$ \\
\hline Diffuse type & $57(29)$ \\
\hline Mixed type & $16(8)$ \\
\hline \multicolumn{2}{|l|}{ Surgical resection } \\
\hline R0 & $150(75)$ \\
\hline $\mathrm{R} 1$ & $16(8)$ \\
\hline $\mathrm{R} 2$ & $33(17)$ \\
\hline \multicolumn{2}{|c|}{ Type of lymphadenectomy } \\
\hline D0 & $5(3)$ \\
\hline D1 & $31(15)$ \\
\hline D2 & $126(63)$ \\
\hline Not related & $39(19)$ \\
\hline \multicolumn{2}{|l|}{ Lymph nodes } \\
\hline Median & 20 \\
\hline Range & $2-69$ \\
\hline \multicolumn{2}{|l|}{ Tumor depth } \\
\hline pTis & $3(2)$ \\
\hline pT1 & $18(9)$ \\
\hline pT2 & $32(16)$ \\
\hline pT3 & $130(65)$ \\
\hline pT4 & $18(9)$ \\
\hline \multicolumn{2}{|l|}{ Nodal status } \\
\hline NO & $69(35)$ \\
\hline N1 & $66(34)$ \\
\hline $\mathrm{N} 2$ & $41(21)$ \\
\hline N3 & $21(11)$ \\
\hline \multicolumn{2}{|l|}{ TNM stage } \\
\hline 0 & $3(2)$ \\
\hline IA & $15(8)$ \\
\hline IB & $19(10)$ \\
\hline II & $38(19)$ \\
\hline IIIA & $49(25)$ \\
\hline IIIB & $25(13)$ \\
\hline IV M0 & $19(10)$ \\
\hline IV M1 & $30(15)$ \\
\hline \multicolumn{2}{|l|}{ Adjuvant therapy } \\
\hline Surgery alone & $76(38)$ \\
\hline Chemoradiotherapy & $125(62)$ \\
\hline
\end{tabular}


the third year, biannually during the fourth and fifth years, and annually after the fifth year. The patients were submitted to abdominal ultrasonography at 4-month intervals during the first 2 years, at 6-month intervals from the third year on, and annually after the fifth year. Computed tomography, nuclear magnetic resonance, and upper digestive endoscopy were performed based on clinical criteria.

The protein expression of the receptors was related to clinical and pathological characteristics such as age, Laurén histological classification, tumor depth, nodal metastases, TNM stage and overall survival.

Overall survival was defined as the time, in months, that elapsed from the date of surgery to the date of death from any cause. The patients lost to follow-up were censored on the date of last contact with the hospital. The study was approved by the Institutional Review Board of the hospital.

Tissue microarray (TMA)

Tissue samples were fixed in buffered $4 \%$ formalin, embedded in paraffin, and used for TMA construction as described [22]. A slide with a representative tumor was selected, and an area of the tumor was circled on the slide. Using TMA technology (Beecher Instruments, Silver Spring, MD, USA), the area of interest in the donor block was cored twice with a needle $1.0 \mathrm{~mm}$ in diameter and the core transferred to a recipient paraffin block.

Immunohistochemistry (IHC)

TMA sections were stained with primary antibodies: HER1 [H11 mouse monoclonal (Dako, Carpinteria, CA, USA); dilution, 1:100], HER2 [A0485 rabbit polyclonal (Dako); dilution, 1:1500], HER3 [RB-9211 rabbit polyclonal (Nterminal; Neomarkers, Fremont, CA, USA); dilution, 1:100], and HER4 [RB-9045 rabbit polyclonal (C-terminal; Neomarkers); dilution, 1:300]. A standard peroxidase-conjugated streptavidin-biotin method was used to detect the staining reaction (LSAB+; Dako). External positive control tissues included samples of placental tissues positive for the antibodies studied. For negative controls, primary antibodies were omitted and phosphate-buffered saline was substituted. Staining was evaluated by light microscopy and interpreted by a pathologist who was blind to the clinical information. Membrane staining was evaluated for HER1, HER2, HER3, and HER4. Staining of HER1, HER3, and HER4 was classified into four categories ( 0 no staining, $1+$ light staining, $2+$ moderate staining, $3+$ strong staining) according to established criteria $[15,23]$. The recommendations of the consensus panel for HER2 in gastric cancer were used for the classification of HER2 [24, 25]. Cytoplasm staining was evaluated for HER1, HER3, and HER4, and also classified into four categories ( 0 no staining, $1+$ light staining, $2+$ moderate staining, $3+$ strong staining) according to the criteria used in a similar study [15]. The sections classified as 0 and $1+$ were considered to be negative and those classified as $2+$ and $3+$ were considered to be positive, for both membrane and cytoplasm expression.

\section{Statistical analysis}

Correlations between receptor expression and clinicopathological characteristics were calculated by the chi-square test. Kappa coefficient and McNemar test were utilized to assess concordance among receptor expression. The study sample contained a large number of patients with long-term survival (Fig. 1), a distribution that permitted the use of the Weibull model with a mixture model incorporating long-term survivors for survival analysis [26-28]. Figures 2 and 3 demonstrate the adequacy of this parametric model to the nonparametric Kaplan-Meier model, which permits its use. The regression model incorporating long-term survivors with Weibull distribution was also used for the study of the prognostic variables. Because the proportionality assumption of the Cox model was not held, the Cox regression model was not an appropriate choice for analyzing the present data. $p$ values $<0.05$ were considered to indicate statistical significance. The analyses were performed using the R software.

\section{Results}

\section{HER 1}

A total of 198 samples were available for HER1 analysis: $9 \%$ with positive membrane staining ( $4 \%$ with a $2+$ score

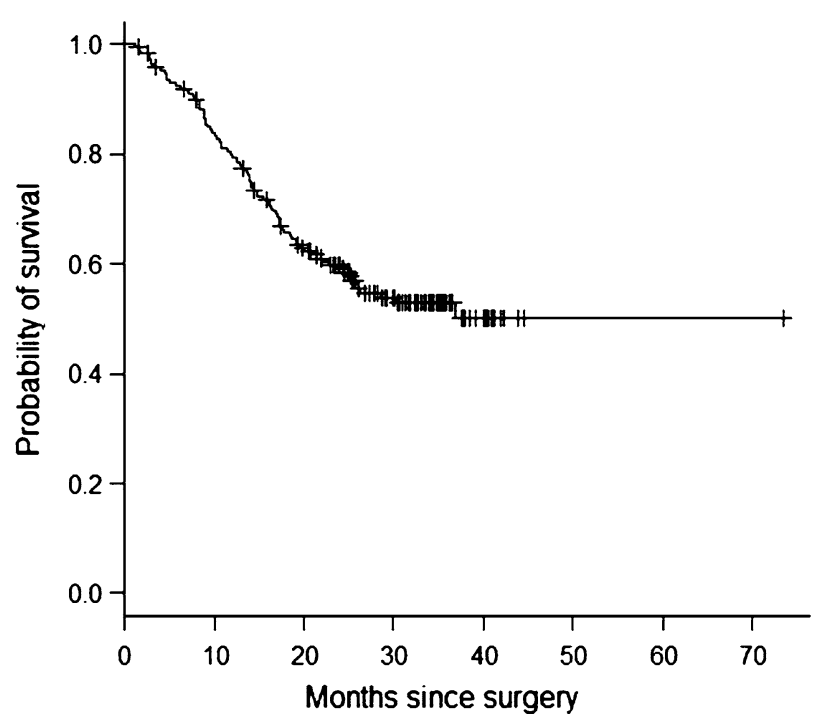

Fig. 1 Kaplan-Meier overall survival curve 

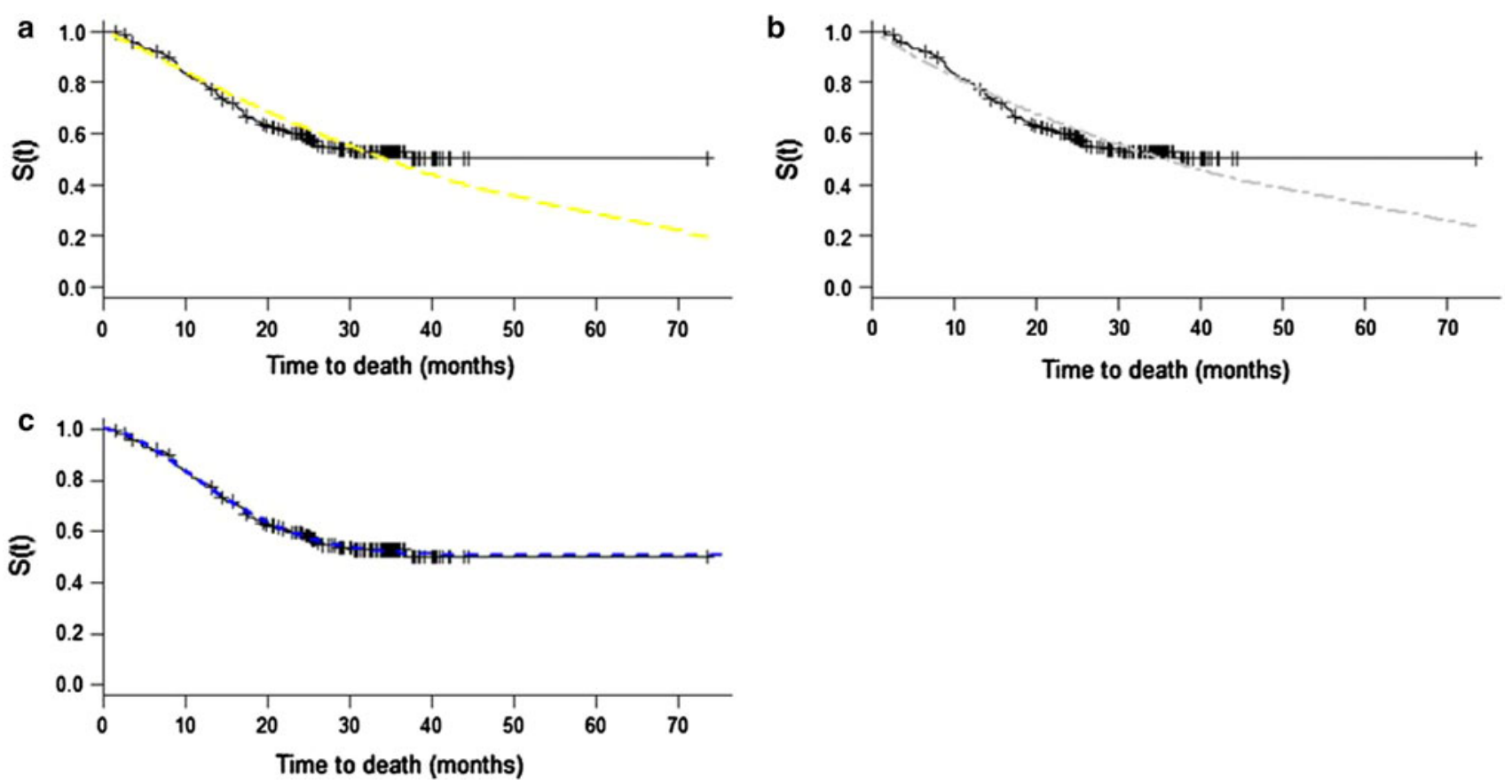

Fig. 2 Survival curves estimated by Kaplan-Meier method and parametric models assuming Weibull (a), exponential (b) and Weibull mixture model incorporating long-term survivors (c) distributions
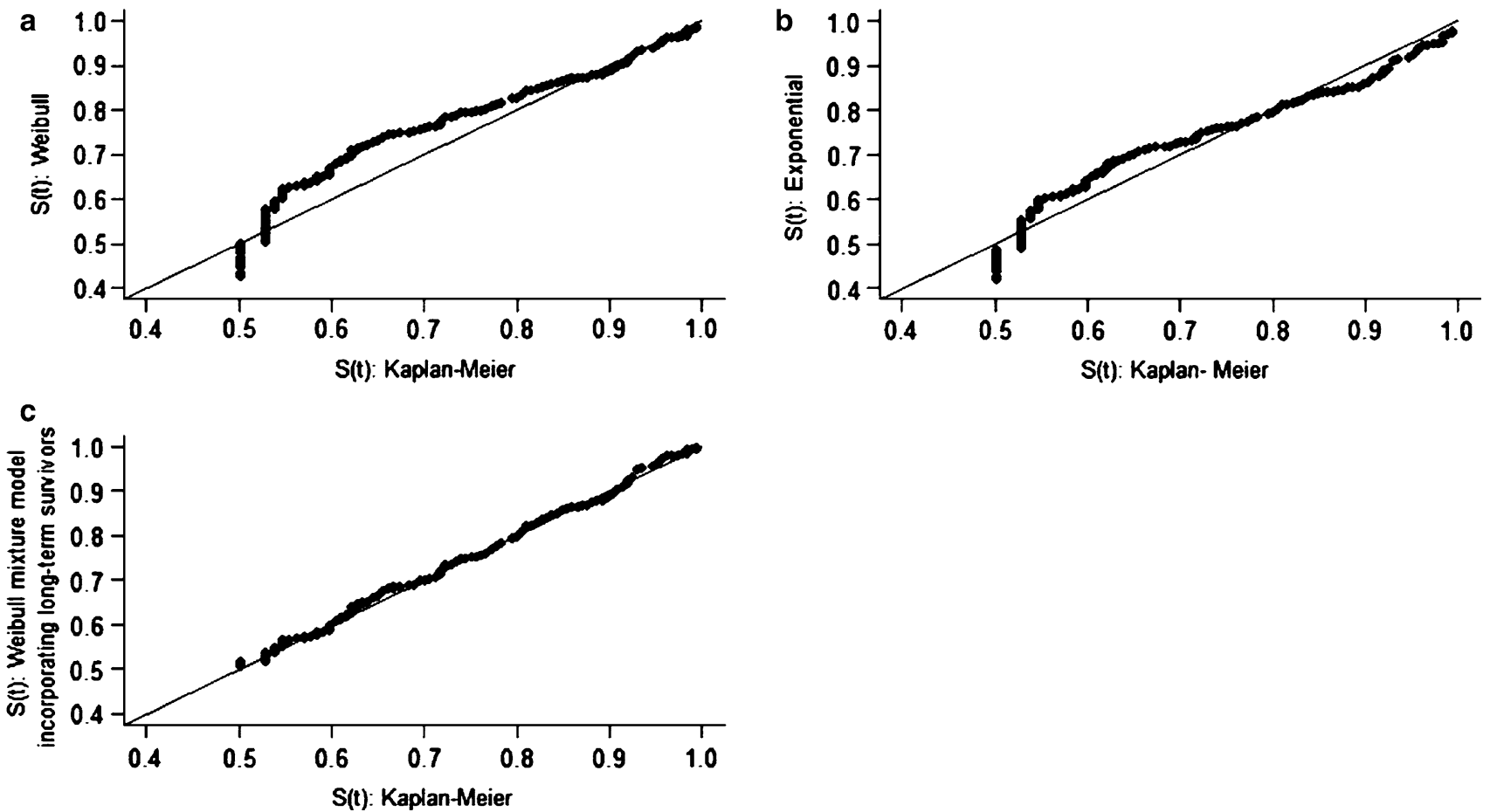

Fig. 3 Graphic representation of survival functions estimated by the Kaplan-Meier method versus survival functions estimated by the parametric models assuming Weibull (a), exponential (b), and Weibull mixture model incorporating long-term survivors (c) distributions

and $5 \%$ with a $3+$ score) and $45 \%$ with positive cytoplasm staining. There was no correlation between HER1 and age, Laurén histological classification, tumor depth, nodal metastases, or TNM stage.
HER2

Thirty-four of the 201 samples (17\%) showed positive membrane HER2 staining (11\% with a $2+$ score and $6 \%$ 
with a $3+$ score). HER2 positivity was correlated with more advanced age $(p=0.011)$ and with the Laurén's intestinal type $(p=0.001)$. There was no correlation between HER2 expression and tumor depth, nodal metastases, or TNM stage.

\section{HER3}

Of the 200 samples available for HER3, only 1 showed membrane reactivity. However, $62 \%$ showed cytoplasm positivity, which was related to more advanced age $(p=0.008)$ and to Laurén's intestinal type $(p<0.001)$. There was no correlation between cytoplasmic HER3 expression and tumor depth, nodal metastases, or TNM stage. The correlation among membrane HER3 expression, clinicopathological characteristics, and overall survival was not evaluated because only one patient showed membrane positivity.

\section{HER4}

Twenty-nine of the 199 samples available (15\%) showed positive membrane HER4 staining, with a $2+$ score in $10 \%$ and a $3+$ score in $5 \% ; 24 \%$ of these showed positive cytoplasm staining. There was no correlation between HER4 expression and age, Laurén histological classification, tumor depth, nodal metastases, or TNM stage. Examples of positive immunohistochemistry for HER1, HER2, HER3, and HER4 are shown in Fig. 4.

\section{Receptors and overall survival}

There was a concordance among expression of the EGFR family receptors, with the exception of membrane HER 1 and HER4, and membrane HER2 and HER4 (Table 2).

Receptor expression did not differ according to disease stage (Table 3).
Fig. 4 Examples of positive immunohistochemistry for HER1 staining in the cytoplasm (a), for HER1 in the membrane (b), for HER2 in the membrane (c), for HER3 in the cytoplasm (d), for HER4 in the cytoplasm (e), and for HER4 in the membrane (f). Magnification: a-f $\times 400$
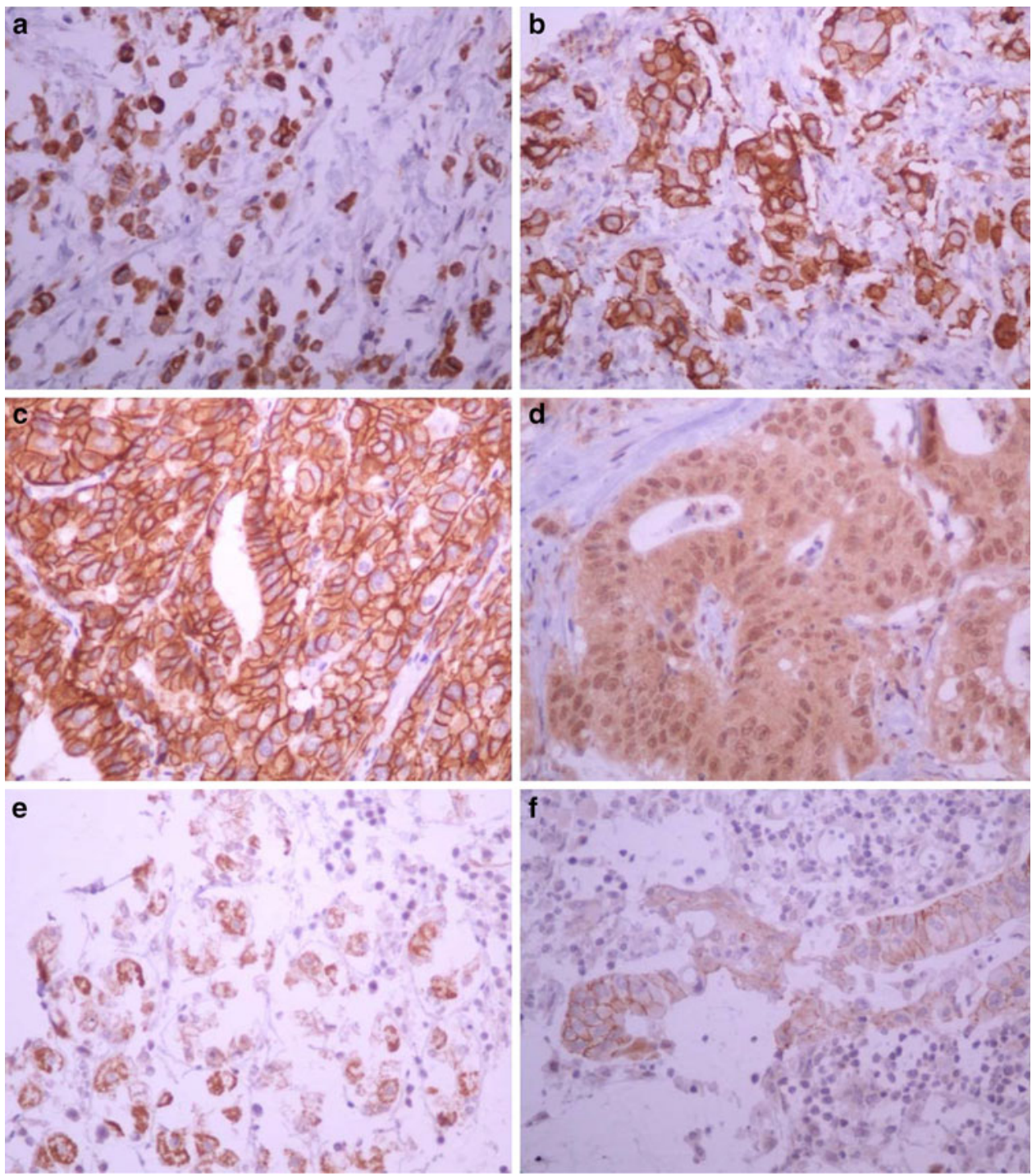


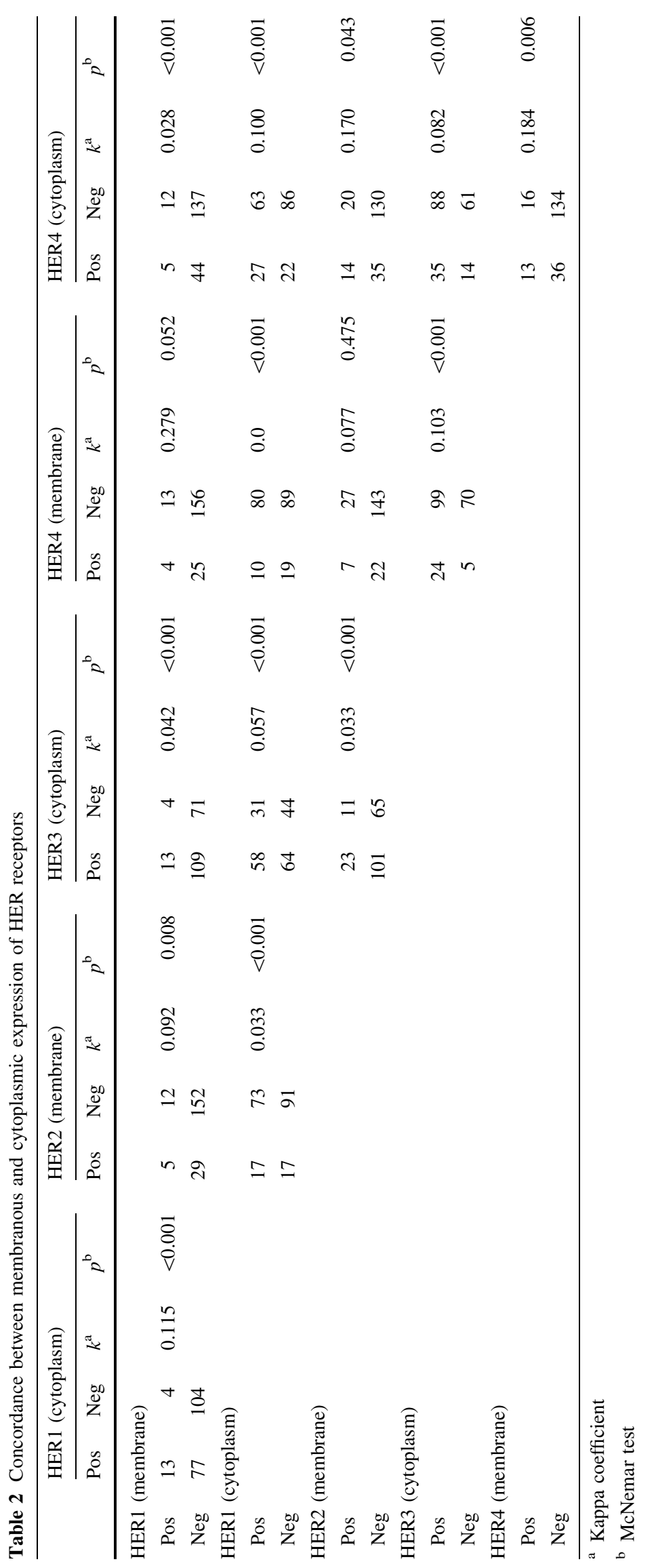


Table 3 Positivity rates of HER receptors according to TNM stage

\begin{tabular}{lllllll}
\hline TNM stage & HER 1 (membrane) & HER1 (cytoplasm) & HER2 (membrane) & HER3 (cytoplasm) & HER4 (membrane) & HER4 (cytoplasm) \\
\hline 0/I/II & $6 / 72(8 \%)$ & $31 / 72(43 \%)$ & $14 / 75(19 \%)$ & $43 / 75(57 \%)$ & $12 / 73(16 \%)$ & $20 / 73(27 \%)$ \\
III/IV & $9 / 93(10 \%)$ & $44 / 93(47 \%)$ & $15 / 93(16 \%)$ & $56 / 92(61 \%)$ & $11 / 93(12 \%)$ & $24 / 93(26 \%)$ \\
IVM1 $^{\text {a }}$ & $1 / 30(3 \%)$ & $14 / 30(47 \%)$ & $5 / 30(17 \%)$ & $23 / 30(77 \%)$ & $4 / 30(13 \%)$ & $5 / 30(17 \%)$ \\
$p$ & 0.545 & 0.258 & 0.907 & 0.176 & 0.692 & 0.321
\end{tabular}

${ }^{a}$ Metastatic disease

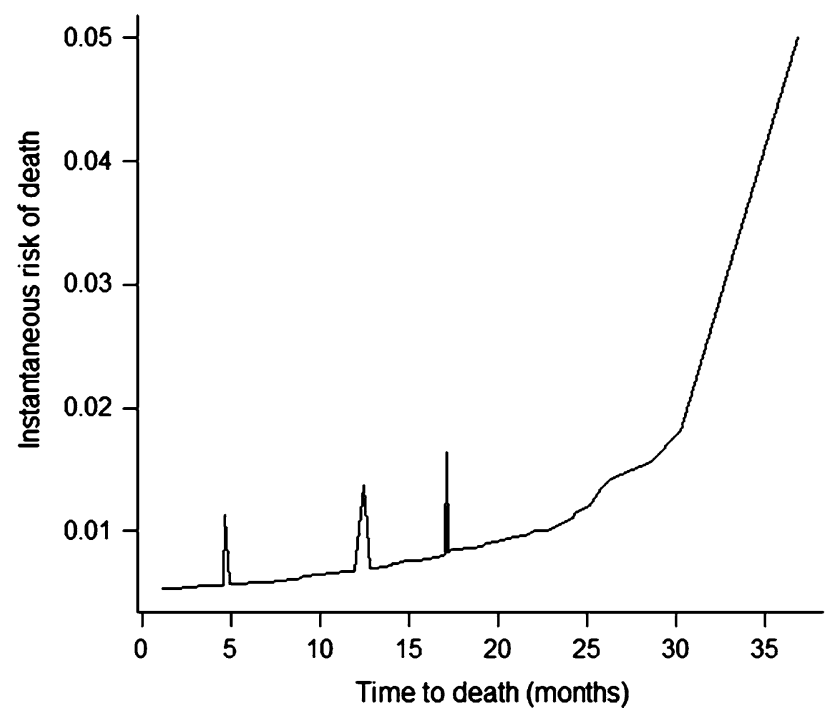

Fig. 5 Instantaneous risk of death
Patients who died during the postoperative period ( $n=12)$ were excluded from survival analysis, with 189 patients remaining in the study. Eighty-three patients $(43.9 \%)$ died and $106(56.1 \%)$ were censored in a median follow-up time of 30.26 months.

The exploration of the Weibull model incorporating long-term survivors allowed the estimation of cure fraction, estimated at $51 \% \quad[95 \%$ confidence interval (CI), $0.42-0.59]$. It was also possible to evaluate the instantaneous risk, which demonstrated an increasing risk of death with time, but was more impressive at 4, 12, and 17 months after surgical treatment in the sample studied (Fig. 5).

The regression model incorporating long-term survivors with Weibull distribution adjusted for age, surgical radicality, type of surgery, Laurén histological classification, adjuvant treatment, TNM stage, and cell receptors revealed that TNM stage was the only variable with a prognostic influence (Fig. 6).

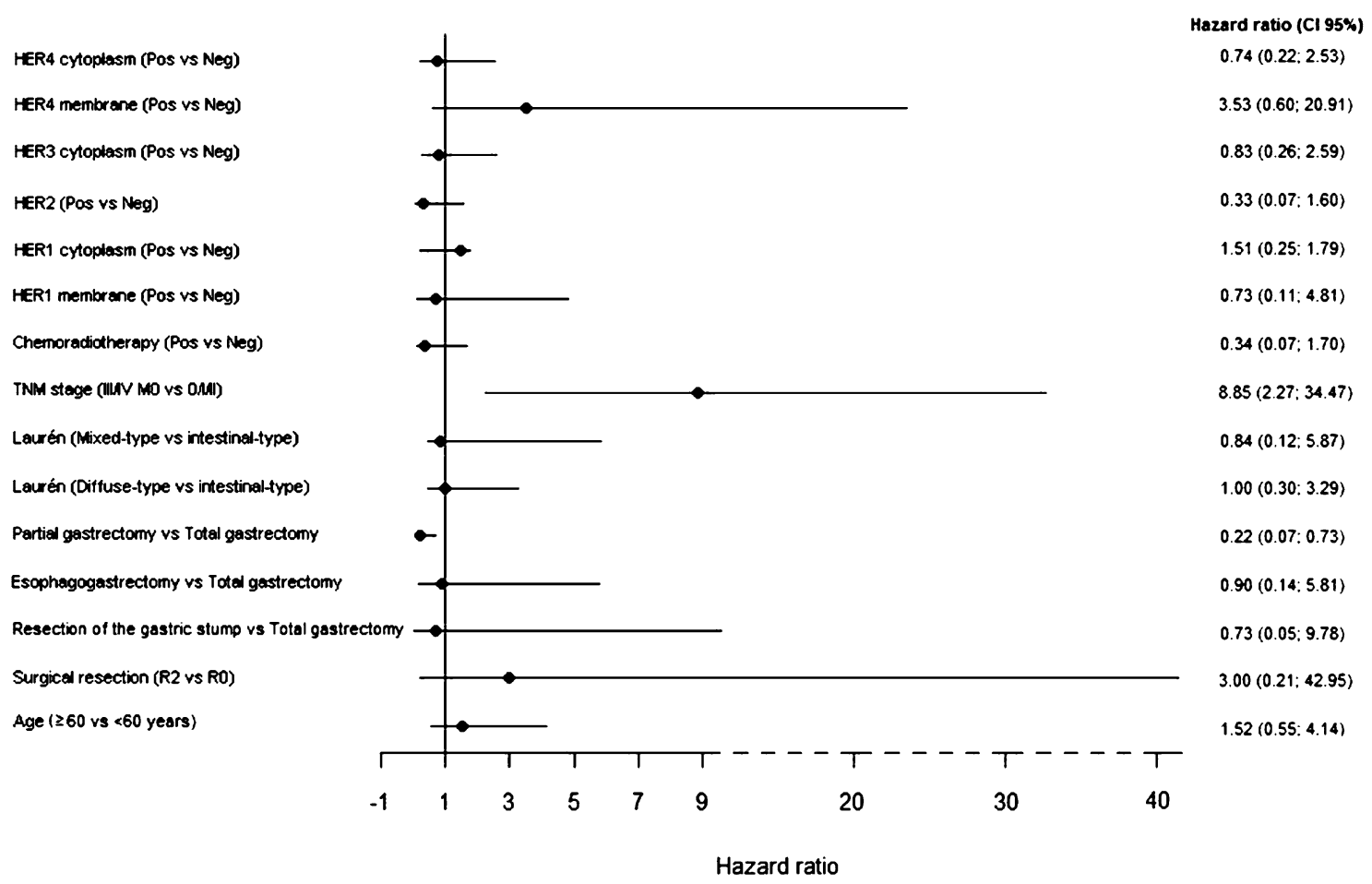

Fig. 6 Estimation of parameters of the regression model incorporating long-term survivors with Weibull distribution and related covariates 


\section{Discussion}

The samples studied represent a heterogeneous population consisting of patients with localized and metastatic gastric adenocarcinoma, with different histological subtypes and subjected to adjuvant chemoradiotherapy or surgery alone. However, the methodology used in the present study did not demonstrate a prognostic value of receptors of the EGFR family in patients with gastric cancer who underwent gastrectomy, as also observed in two major studies that evaluated the prognostic value of the EGFR family in gastric cancer [15, 17].

Positivity for the expression of the EGFR family receptors depends on the sample studied and the methodology used. Factors such as prevalence of Laurén histological type, population age, quality of the samples used, antibodies employed, criteria adopted, and different methodologies among studies are probably responsible for the variability detected in the literature.

A study conducted on a Japanese population that also had heterogeneous characteristics regarding disease stage and further treatment received by the patients, adopting the same criteria for the classification of receptors of the EGFR family as used in the present study but without immunohistochemical evaluation by TMA, suggested that HER3 may also have a prognostic influence on gastric cancer [14].

Evaluation in a Western population, also with localized and metastatic disease but without the use of adjuvant treatment, detected a prognostic influence of HER2 and HER3 expression by univariate analysis; however, this was not reproduced by multivariate analysis [10, 17]. This study [17], similar to the present one, used TMA for the reading of the immunohistochemical analysis, but employed different criteria for the interpretation of HER1, HER3, and HER4 expression, in addition to also employing fluorescence in situ hybridization (FISH).

There still is no consensus about the criteria to be adopted for the reading of these three receptors in gastric cancer that resembles those available for the interpretation of HER2 expression [24, 25]. The rates of expression of the receptors observed in the present study were similar to those of the study conducted on a Western population, whereas the study on the Japanese population demonstrated much higher levels of HER1 expression in the membrane and of HER4 in the cytoplasm (Table 4). So far, there are no data indicating that race and geographic location may be factors responsible for this variability.

The expression of HER 1 in gastric cancer ranges from 2 to $44 \%$ [29-32], and the $9 \%$ positivity observed in the present study is within recorded limits. The prognostic value of its expression is controversial, with some data even suggesting that HER1 overexpression may predict a higher risk of disease recurrence after adjuvant treatment with platinum and fluoropyrimidine [32, 33].

The rate of HER2 expression in gastric cancer ranges from 8 to $34 \%$, with a mean of $17.6 \%$ [24]. Recent systematic review without meta-analysis involving more than 11,000 patients showed $18 \%$ of HER2 overexpression and suggests a poorer overall survival for these patients [34]. The $17 \%$ positivity and the frequent association between HER2 expression and Laurén's intestinal type were also observed in the present study.

In the present study there was also an association between HER2 overexpression and advanced age, in agreement with the findings of a recent study that detected a rate of HER 2 overexpression of only $3 \%$ and a rate of HER2 amplification of $5 \%$ in patients younger than 45 years [35]. These data support the hypothesis that gastric cancer of early onset has a different profile of molecular expression than disease of late onset [36, 37].

In the present sample, HER3 as well as HER2 overexpression was associated with Laurén's intestinal type and advanced age. Studies on HER3 expression in gastric cancer are still scarce, but the association with Lauren's histological type is controversial, with a relationship having been detected with both the intestinal type [17] and the diffuse type [16]. The association with advanced age had not been reported previously [15-17]. In the present study, the association between HER2 and HER3 expression, and the finding of similar clinicopathological associations between the expression of these two receptors, contributes
Table 4 Comparison of rates of HER receptor expression in gastric cancer

IHC immunochemistry, FISH fluorescence in situ hybridization, $N R$ not related

\begin{tabular}{llll}
\hline Receptors & Hayashi et al. [15] & Begnami et al. [17] & Jácome et al. [53] \\
\hline HER 1 (membrane) (\%) & 30 & 2 & 9 \\
HER1 (cytoplasm) (\%) & NR & NR & 45 \\
HER2 (\%) & 18 (IHC) & 12 (IHC) & 17 (IHC) \\
& & 8 (FISH) & \\
HER3 (membrane) (\%) & 13 & $<1$ & 62 \\
HER3 (cytoplasm) (\%) & 58 & 64 & 15 \\
HER4 (membrane) (\%) & 22 & 18 & 24 \\
HER4 (cytoplasm) (\%) & 84 & 23 & \\
\hline
\end{tabular}


to the hypothesis that, among the heterodimers of the EGFR family, these two receptors are those expressed at high frequency [17]. This finding is of relevant importance in the signaling of the phosphatidyl inositol-3 kinase pathway [38, 39], a fact that makes HER3 a potential target for the treatment of gastric cancer.

The absence of tyrosine kinase activity of HER 3 initially led to the idea that this is a receptor of minor importance in cell proliferation and differentiation, but increasing evidence has demonstrated its role as an important regulator of HER2 activity [40]. The benefit demonstrated by the addition of pertuzumab - a drug that inhibits HER2-HER3 heterodimerization-to trastuzumab in the treatment of HER2-positive breast cancer supports the importance of this heterodimer in the proliferation of tumor cells with HER2 overexpression or amplification [41] and suggests this new monoclonal antibody is a potentially effective agent for the treatment of gastric cancer [42].

HER4 did not show a prognostic value in the present study or in similar investigations [15, 17]. Some data regarding breast cancer have suggested that the expression of receptors of the EGFR family should not be analyzed and interpreted separately as distinct units. The prognostic value of these receptors is probably determined by their interrelationship [21, 43].

Coupling the distribution of survival data to a predefined model permits their analysis by parametric models, which are known to allow a more detailed and reliable interpretation of the data [44]. During long-term follow-up and in the presence of a significant group of long-term survivors, the nonparametric models lose their power of analysis and should be preferentially avoided [45]. A frequent occurrence in survival analysis is the detection of individuals who, after a long follow-up period, do not present the occurrence of the event of interest. In the present study, we chose to analyze the data using a parametric model in view of the adaptation of the distribution of survival data to the Weibull model with a mixture model incorporating longterm survivors, which permitted the incorporation of individuals with a low probability of death as the event of interest.

Although the Cox model is the method most frequently used in analyses involving time until a given event, the assumption of risk proportionality among the categories of a given covariable is not always satisfied. Adjustment to the Weibull model demonstrated the flexibility of the parametric models regarding the easy incorporation of the effects of covariables in their parameters, in addition to the ability to provide more information about the nature of the distribution of survival time and of the behavior of the risk function along time, data that nonparametric or semiparametric models do not provide [46]. According to the reporting recommendations for tumor marker prognostic studies, the biological markers were included in the model of multivariate analysis, with a parametric regression model being used [10, 47].

The heterogeneity of HER2 expression in gastric cancer leads to questioning the value of TMA as a method for the assessment of HER2 status in this neoplasia. The evaluation of expression and amplification using samples that contain a greater portion of tumor tissue may perhaps be more representative for the test and may reduce the probability of false-negative results. However, this method has been extensively used for the reliable detection of biomarkers, including those with heterogeneous distribution in tumor tissue [48]. In addition, this method simulates the gastric biopsies performed by upper digestive endoscopy, which have well-defined criteria for the evaluation of HER2 status and have been used in various studies [17, 49, 50]. On the other hand, there is a need for additional studies that will validate TMA as an appropriate method for the evaluation of HER2 status.

Despite the high level of concordance between IHC and in situ hybridization methods to evaluate HER2 expression in gastric cancer [51], the current recommendations suggest that samples of patients with IHC $2+$ should be referred to in situ hybridization techniques [52]. In the present study, the silver-enhanced in situ hybridization (SISH) method was used, but, perhaps because of the long storage time of the formalin-fixed paraffin-embedded blocks, the reading was not of sufficiently high quality to be reported, which constitutes a limitation of the present study.

The absence of prognostic value of HER2 in gastric cancer demonstrated in some studies does not exclude the predictive value of this receptor regarding anti-HER2 therapies, as demonstrated by the ToGA study [11]. In breast cancer, this receptor has been demonstrated to be a prognostic and predictive marker of benefit regarding antiHER2 therapies, but, since the introduction of trastuzumab, HER2 expression is no longer a prognostic marker [6]. Large prospective trials with a validated methodology are needed to determine the real prognostic value of HER2 overexpression.

Acknowledgments This work was supported by Fundação Waldemar Barnsley Pessoa, Brazil.

Conflict of interest None declared.

Open Access This article is distributed under the terms of the Creative Commons Attribution License which permits any use, distribution, and reproduction in any medium, provided the original author(s) and the source are credited.

\section{References}

1. Nicholson RI, Gee JM, Harper ME. EGFR and cancer prognosis. Eur J Cancer. 2001;37(suppl 4):S9-15. 
2. Sithanandam G, Anderson LM. The ERBB3 receptor in cancer and cancer gene therapy. Cancer Gene Ther. 2008;15(7):413-48.

3. Salomon DS, Brandt R, Ciardiello F, Normanno N. Epidermal growth factor-related peptides and their receptors in human malignancies. Crit Rev Oncol Hematol. 1995;19(3):183-232.

4. Gravalos C, Jimeno A. HER2 in gastric cancer: a new prognostic factor and a novel therapeutic target. Ann Oncol. 2008;19(9): 1523-9.

5. Hudis CA. Trastuzumab-mechanism of action and use in clinical practice. N Engl J Med. 2007;357(1):39-51.

6. Slamon DJ, Leyland-Jones B, Shak S, Fuchs H, Paton V, Bajamonde A, et al. Use of chemotherapy plus a monoclonal antibody against HER2 for metastatic breast cancer that overexpresses HER2. N Engl J Med. 2001;344(11):783-92.

7. Geyer CE, Forster J, Lindquist D, Chan S, Romieu CG, Pienkowski T, et al. Lapatinib plus capecitabine for HER2-positive advanced breast cancer. N Engl J Med. 2006;355(26):2733-43.

8. Gravalos C, Gomez-Martin C, Rivera F, Ales I, Queralt B, Marquez A, et al. Phase II study of trastuzumab and cisplatin as first-line therapy in patients with HER2-positive advanced gastric or gastroesophageal junction cancer. Clin Transl Oncol. 2011;13(3):179-84.

9. Iqbal S, Goldman B, Fenoglio-Preiser CM, Lenz HJ, Zhang W, Danenberg KD, et al. Southwest Oncology Group study S0413: a phase II trial of lapatinib (GW572016) as first-line therapy in patients with advanced or metastatic gastric cancer. Ann Oncol. 2011;22(12):2610-5.

10. Bohanes P, Loupakis F, Labonte MJ, Wakatsuki T, Lenz HJ. HER Majesty's a pretty nice girl but she changes from day to day. J Clin Oncol. 2012;30(4):465-6.

11. Bang YJ, Van Cutsem E, Feyereislova A, Chung HC, Shen L, Sawaki A, et al. Trastuzumab in combination with chemotherapy versus chemotherapy alone for treatment of HER2-positive advanced gastric or gastro-oesophageal junction cancer (ToGA): a phase 3, open-label, randomised controlled trial. Lancet. 2010;376(9742):687-97.

12. Terashima M, Ochiai A, Kitada K, Ichikawa W, Kurahashi I, Sakuramoto S, et al. Impact of human epidermal growth factor receptor (EGFR) and ERBB2 (HER2) expressions on survival in patients with stage II/III gastric cancer, enrolled in the ACTS-GC study. J Clin Oncol 2011;29:15s (suppl) (abstr 4013)

13. Shah MA, Janjigian YY, Pauligk C, Werner D, Kelsen DP, Jaeger $\mathrm{E}$, et al. Prognostic significance of human epidermal growth factor-2 (HER2) in advanced gastric cancer: a US and European international collaborative analysis. J Clin Oncol 2011;29:15s (suppl) (abstr 4014)

14. Park YS, Ryu M, Park HJ, Kim HJ, Ryoo B, Yook JH, et al. HER2 status as an independent prognostic marker in patients with advanced gastric cancer receiving adjuvant chemotherapy after curative gastrectomy. J Clin Oncol 2011;29:15s (suppl) (abstr 4084)

15. Hayashi M, Inokuchi M, Takagi Y, Yamada H, Kojima K, Kumagai J, et al. High expression of HER3 is associated with a decreased survival in gastric cancer. Clin Cancer Res. 2008;14(23):7843-9.

16. Zhang XL, Yang YS, Xu DP, Qu JH, Guo MZ, Gong Y, et al. Comparative study on overexpression of HER2/neu and HER3 in gastric cancer. World J Surg. 2009;33(10):2112-8.

17. Begnami MD, Fukuda E, Fregnani JH, Nonogaki S, Montagnini AL, da Costa WL Jr, et al. Prognostic implications of altered human epidermal growth factor receptors (HERs) in gastric carcinomas: HER 2 and HER 3 are predictors of poor outcome. J Clin Oncol. 2011;29(22):3030-6.

18. Kim MA, Lee HS, Lee HE, Jeon YK, Yang HK, Kim WH. EGFR in gastric carcinomas: prognostic significance of protein overexpression and high gene copy number. Histopathology. 2008;52(6):738-46.
19. Suo Z, Risberg B, Kalsson MG, Willman K, Tierens A, Skovlund $\mathrm{E}$, et al. EGFR family expression in breast carcinomas. c-erbB-2 and c-erbB-4 receptors have different effects on survival. J Pathol. 2002;196(1):17-25.

20. Kountourakis P, Pavlakis K, Psyrri A, Rontogianni D, Xiros N, Patsouris E, et al. Prognostic significance of HER3 and HER4 protein expression in colorectal adenocarcinomas. BMC Cancer. 2006;6:46.

21. Memon AA, Sorensen BS, Meldgaard P, Fokdal L, Thykjaer T, Nexo E. The relation between survival and expression of HER1 and HER 2 depends on the expression of HER3 and HER4: a study in bladder cancer patients. Br J Cancer. 2006;94(11): 1703-9.

22. Kononen J, Bubendorf L, Kallioniemi A, Barlund M, Schraml P, Leighton $\mathrm{S}$, et al. Tissue microarrays for high-throughput molecular profiling of tumor specimens. Nat Med. 1998;4(7): 844-7.

23. Witton CJ, Reeves JR, Going JJ, Cooke TG, Bartlett JM. Expression of the HER1-4 family of receptor tyrosine kinases in breast cancer. J Pathol. 2003;200(3):290-7.

24. Hofmann M, Stoss O, Shi D, Buttner R, van de Vijver M, Kim W, et al. Assessment of a HER2 scoring system for gastric cancer: results from a validation study. Histopathology. 2008;52(7): 797-805.

25. Ruschoff J, Dietel M, Baretton G, Arbogast S, Walch A, Monges $\mathrm{G}$, et al. HER2 diagnostics in gastric cancer-guideline validation and development of standardized immunohistochemical testing. Virchows Arch. 2010;457(3):299-307.

26. Farewell VT. The use of mixture models for the analysis of survival data with long-term survivors. Biometrics. 1982;38(4): 1041-6.

27. Perperoglou A, Keramopoullos A, van Houwelingen HC. Approaches in modelling long-term survival: an application to breast cancer. Stat Med. 2007;26(13):2666-85.

28. Lam KF, Fong DY, Tang OY. Estimating the proportion of cured patients in a censored sample. Stat Med. 2005;24(12):1865-79.

29. Lieto E, Ferraraccio F, Orditura M, Castellano P, Mura AL, Pinto $\mathrm{M}$, et al. Expression of vascular endothelial growth factor (VEGF) and epidermal growth factor receptor (EGFR) is an independent prognostic indicator of worse outcome in gastric cancer patients. Ann Surg Oncol. 2008;15(1):69-79.

30. Galizia G, Lieto E, Orditura M, Castellano P, Mura AL, Imperatore $\mathrm{V}$, et al. Epidermal growth factor receptor (EGFR) expression is associated with a worse prognosis in gastric cancer patients undergoing curative surgery. World J Surg. 2007;31(7): 1458-68.

31. Mammano E, Belluco C, Sciro M, Mencarelli R, Agostini M, Michelotto M, et al. Epidermal growth factor receptor (EGFR): mutational and protein expression analysis in gastric cancer. Anticancer Res. 2006;26(5A):3547-50.

32. Gamboa-Dominguez A, Dominguez-Fonseca C, QuintanillaMartinez L, Reyes-Gutierrez E, Green D, Angeles-Angeles A, et al. Epidermal growth factor receptor expression correlates with poor survival in gastric adenocarcinoma from Mexican patients: a multivariate analysis using a standardized immunohistochemical detection system. Mod Pathol. 2004;17(5):579-87.

33. Kim JS, Kim MA, Kim TM, Lee SH, Kim DW, Im SA, et al. Biomarker analysis in stage III-IV (M0) gastric cancer patients who received curative surgery followed by adjuvant 5-fluorouracil and cisplatin chemotherapy: epidermal growth factor receptor (EGFR) associated with favourable survival. Br J Cancer. 2009;100(5):732-8.

34. Chua TC, Merrett ND. Clinicopathologic factors associated with HER2-positive gastric cancer and its impact on survival outcomes-a systematic review. Int J Cancer. 2012;130(12): 2845-56. 
35. Moelans CB, Milne AN, Morsink FH, Offerhaus GJ, van Diest PJ. Low frequency of HER2 amplification and overexpression in early onset gastric cancer. Cell Oncol (Dordr). 2011;34(2):89-95.

36. Milne AN, Carvalho R, Morsink FM, Musler AR, de Leng WW, Ristimaki A, et al. Early-onset gastric cancers have a different molecular expression profile than conventional gastric cancers. Mod Pathol. 2006;19(4):564-72.

37. Milne AN, Sitarz R, Carvalho R, Carneiro F, Offerhaus GJ. Early onset gastric cancer: on the road to unraveling gastric carcinogenesis. Curr Mol Med. 2007;7(1):15-28.

38. Lee-Hoeflich ST, Crocker L, Yao E, Pham T, Munroe X, Hoeflich KP, et al. A central role for HER3 in HER2-amplified breast cancer: implications for targeted therapy. Cancer Res. 2008; 68(14):5878-87.

39. Hsieh AC, Moasser MM. Targeting HER proteins in cancer therapy and the role of the non-target HER3. Br J Cancer. 2007;97(4):453-7.

40. Holbro T, Beerli RR, Maurer F, Koziczak M, Barbas CF 3rd, Hynes NE. The ErbB2/ErbB3 heterodimer functions as an oncogenic unit: ErbB2 requires ErbB3 to drive breast tumor cell proliferation. Proc Natl Acad Sci USA. 2003;100(15):8933-8.

41. Baselga J, Cortes J, Kim SB, Im SA, Hegg R, Im YH, et al. Pertuzumab plus trastuzumab plus docetaxel for metastatic breast cancer. N Engl J Med. 2012;366(2):109-19.

42. Yamashita-Kashima Y, Iijima S, Yorozu K, Furugaki K, Kurasawa $\mathrm{M}$, Ohta $\mathrm{M}$, et al. Pertuzumab in combination with trastuzumab shows significantly enhanced antitumor activity in HER2-positive human gastric cancer xenograft models. Clin Cancer Res. 2011;17(15):5060-70.

43. Karamouzis MV, Badra FA, Papavassiliou AG. Breast cancer: the upgraded role of HER-3 and HER-4. Int J Biochem Cell Biol. 2007;39(5):851-6.

44. Lee ET, Wang JW (2003) Statistical methods for survival data analysis, vol 1, 3rd edn. Wiley, Hoboken, NJ
45. Gamel JW, Vogel RL. Comparison of parametric and non-parametric survival methods using simulated clinical data. Stat Med. 1997;16(14):1629-43.

46. Harrel FE Jr. Predicting outcomes: applied survival analysis and logistic regression, vol 1. Charlottesville: University of Virginia; 1996.

47. McShane LM, Altman DG, Sauerbrei W, Taube SE, Gion M, Clark GM. Reporting recommendations for tumor marker prognostic studies. J Clin Oncol. 2005;23(36):9067-72.

48. Camp RL, Neumeister V, Rimm DL. A decade of tissue microarrays: progress in the discovery and validation of cancer biomarkers. J Clin Oncol. 2008;26(34):5630-7.

49. Kunz PL, Mojtahed A, Fisher GA, Ford JM, Chang DT, Balise $\mathrm{RR}$, et al. HER2 expression in gastric and gastroesophageal junction adenocarcinoma in a US population: clinicopathologic analysis with proposed approach to HER2 assessment. Appl Immunohistochem Mol Morphol. 2011;20(1):13-24.

50. Ismail HM, Moneer M, El-Baradie M, Khorshid O, Touny A. Clinicopathologic and prognostic significance of overexpression of HER-2/neu and p53 oncoproteins in gastric carcinoma using tissue microarray. J Egypt Natl Canc Inst. 2007;19(2):147-57.

51. Park YS, Hwang HS, Park HJ, Ryu MH, Chang HM, Yook JH, et al. Comprehensive analysis of HER2 expression and gene amplification in gastric cancers using immunohistochemistry and in situ hybridization: which scoring system should we use? Hum Pathol. 2012;43(3):413-22.

52. Ruschoff J, Hanna W, Bilous M, Hofmann M, Osamura RY, Penault-Llorca F, et al. HER2 testing in gastric cancer: a practical approach. Mod Pathol. 2012;25(5):637-50.

53. Jácome AA, Wohnrath DR, Scapulatempo Neto C, Carneseca EC, Nunes JS, Viana LS, et al. Prognostic value of epidermal growth factor receptors (EGFR) on overall survival of gastric cancer patients. J Clin Oncol 2012;30:15s (suppl) (abstr e14599) 